\section{The Effect of Environment and Culture on Vegetable Seed Quality}

\author{
James T. Watkins
}

$\mathrm{T}$ his paper is an overview of how the seed industry deals with environmental and cultural considerations to provide quality vegetable seed. Before discussing the impacts of cultural practices and environment on seed quality, it is important to describe what is generally meant by seed quality. Seed quality can be generally defined by the seeds level of performance in six areas: 1) percent germination-the higher the better, 2) physical purity-seed should be free of other crop seed, weed seed, and inert materials, 3) cultivar purity-the kind, type, shape, size, color, and disease resistances should be characteristic of that vegetable cultivar, or, simply put, trueness-to-type, 4) genetic purity-the percent hybridity of the seed lot should be acceptable for the species and cultivar, 5) seed health-the seed should be free of seedborne diseases, 6) seed vigor-using the definiion adopted by the Assn. of Official Seed Analysts (AOSA, 1983) "Seed vigor comprises those seed properties which determine the potential for rapid, uniform emergence, and development of normal seedlings under a wide range of field conditions." herefore, with seed vigor, as with percent seed fermination, the higher the better. Using these six criteria for description of seed quality, the environment and cultural practices are selected or modified to achieve the highest possible seed quality levels.

Environment is the main determining factor that decides when, where, how, and what quality of vegetable seed is produced. In many seed crops [the biennials crucifers, onion (Allium cepa), carrot (Daucus carota)], specific vernalization and photoperiodic requirements must be met to achieve uniform flower stalk extension and economic levels of seed yields. In some cases, "tricks," such as the use of large commercial coolers to vernalize carrot stecklings, can be used to produce a seed crop here normal temperatures would not allow for adequate flower stalk initiation. However, these tricks are the exception to the common practice. In addition to meeting specific temperature or photo-

Sakata Seed America, Inc., Salinas Research Station, 105 Boronda Rd., Salinas, CA 93907. periodic requirements, vegetable seed crops have been produced in areas that typically have low rainfall and humidity during the growing season and dry weather during harvest. Such environments are less favorable to plant disease. Because of the importance of low humidity during seed production and dry weather at harvest, the western United States has become the focal location of seed production. Recently, however, the increased costs of seed production and maintenance of seed inventories for seasonal carryover have resulted in increased production of field-grown seed crops in Central and South America and in Australia. Lower production costs and the ability to produce seed in the winter (the season just previous to sale) has offset seed transportation costs and the inconvenience of doing business outside of the United States.

Hand pollination is commonly used to produce hybrid vegetable seed crops that do not benefit from genetic separation of sexes [cucumber (Cucumis sativus)], chemical induction of sexual separation [squash (Cucurbita pepo)], cytoplasmic male sterile systems (onion and carrot), or self-incompatibility (brassicas). The location of hand-produced hybrids is probably controlled more by the economic environment than by the environment of a location. The availability of abundant, low-cost labor is a major concern in selecting sites for hand-produced hybrid vegetable seed. Taiwan and Japan have been the traditional sites of handproduced hybrid vegetable seed; however, Central and South America, China, Thailand, and India have recently been added as production sites.

There is a wide array of cultural practices that seed producers and growers must manage to be successful and to optimize seed yieldsand quality. Some of the cultural practices for producing vegetable seed crops are very similar to those used for growing the vegetable commodity. Cultural practices for seed production of tomato (Lycopersicon esculentum), pepper (Capsicum spp.), and cucurbits are very similar to the practices used for growing the vegetables themselves. However, seed production cultural practices for crops such as brassicas, onion, carrot, and lettuce (lactuca sativa) se very different. The reason is that practices promoting the growth and development of the vegetable for these species are not always advantageous for producing seed. Additionally, these seed crops take much more time to mature than their vegetable components. Crops like broccoli Brassica oleracea var. botrytis), cabbage (B. oleracea var. capitata), carrot, and long-day onion take three to four times longer to produce seeds ran to produce vegetables.

Some of the cultural practices that the grower and producer of vegetable seed must consider are: soil type and fertility, growing site crop history, plant density, crop nutrition, pest control, soil moisture control, male : female ratio and coincidence of bloom of male and female plants in hybrid crops, pollination, isolation and competition, and method and timing of seed harvest.
Soil type and fertility determine, in large part irrigation practices and the amount and kind of fertilizer that will be applied. Generally, moderately fine-textured soils are preferred for seed production. These lend themselves to furrow irrigation and have good water- and nutrient-holding capacities, which reduces the number of irrigations or sidedressings of fertilizer required to produce a crop.

The review of crop histories for any potential seed production site is very important. Previous crops have a tremendous impact on the success of any seed crop, especially in the areas of residual fertilizer or herbicide, volunteers from similar crops, and the amount of disease pressure the seed crop may encounter. In producing a seed crop, it is generally preferable to follow grain or hay crops, rather than other seed crops, vegetable crops or field or sweet corn (Zea mays). Disease pressures from crop or pathogen carryover are reduced following grain or hay crops. The use of the herbicide atrazine(2-chloro-4-ethylamino-6-isopropylamino5-triazine) in corn production may limit tremendously the production of subsequent crops due to its lengthy persistence in the soil.

Plant spacing between and within rows affects the potential for seed yield and seed quality. Good air movement in a seed crop is important for reducing disease pressure and improving pesticide coverage when chemicalsare used. Low plant density will increase the ability of weeds to establish, and, in some cases, if plant density is too great the potential for the crop to lodge before harvest is increased. Crop density will also affect cultivation practices and the ease of harvest, especially in the separation of male and female rows.

Crop nutrition of annual seed crops is very similar to that of the vegetable; however, for biennial seed crops take care to control the vegetative growthstage. It can be counterproductive to induce overly lush vegetative growth in biennial seed crops. Large, lush plants are more sensitive to freeze injury, decay, and frost-heaving than smaller, hardier plants when overwintering is required for vernalization. However, adequate nutrition for the biennial seed crops must be provided for the sexual growth stage. This is often done by an early spring sidedressing of granular or liquid fertilizer, or by providing fertilizer in the irrigation water. Except in cases of severe nutrient deficiencies, a seed crop will set and produce seed. However, crop nutrition affects the amount and quality of seed that can be produced.

The control of weeds, diseases, insects, and other pests is one of the most costly and important activities performed by the vegetable seed grower. Weed competition must be reduced and as weedtree an environment as economically possible maintained. Weeds deter crop growth and productivity as well as seed harvest and physical quality. The presence of weed seed can be a significant problem during seed conditioning, and noxious weed seed may make the seed crop 
unsalable. Weed control is generally achieved by the use of herbicides and cultivation.

Vegetable seeds are subject to the same disease and insect problems as edible vegetables In addition, some disease and arthropod pests that are no concern to the vegetable grower can be very important to the seed grower. Attention must also be paid to seed-borne diseases, which require a complete program of control. Control begins well before going to the production field and must be continued through seed harvest.

Disease-carrying insect vectors and seeddamaging insects and similar pests must be controlled without injuring or reducing honeybees or other pollinators and beneficial insect populations.

An adequate supply of soil moisture is necessary to maximize seed yields and seed quality. Seed yields will typically be reduced with moisture stress early in plant development, during bloom, or during seed set. Seed size and vigor can be sacrificed if the seed crop experiences a moisture deficiency or is prematurely dried-down during the seed development or maturation phase. Furrow or drip irrigation should be used whenever possible rather than overhead irrigation. Overhead irrigation of seed crops can lead to the development and spread of seed and field diseases and can negate the benefit of production in drier climates.

The male : female ratio and its arrangement in field-produced hybrid seed crops are used to maximize seed yields and minimize inbred seed. The ratio of male to female rows is largely determined by the amount of pollen produced by the male row and the spatial proximity needed to achieve pollen transfer to the female rows, either by insect vectors or wind. The number of male and female rows and their planting dates also are controlled by the need for bloom of the female and male rows to coincide, or "nick." When nicking is not a problem, the parent rows can be planted at the same time. However, for many of the vegetable seed crops, nicking of male and female bloom is a problem. There are a number of commonly used methods of solving the nick problem betweenmale and female plants. One method is to plant the male rows earlier or later than or at the same time to bracket the female planting to improve nick. Another method is to cut or prune back male or female plants to encourage lateral branching and later bloom, but or course this method cannot be used on onions or sweet corn. The third method to improve the coincidence of bloom for male and female rows is to use transplants, stecklings, or bulbs for one parent and to direct-seed the other parent. Solutions to parental nicking problems should be developed early by the plant breeder and refined during pilot seed production.

Many field-produced hybrid and open-pollinated vegetable seed crops require pollinators. Domesticated honey bees are typically used, but other pollinators, e.g., flies, are sometimes employed. Hives are usually placed around and/or within seed fields to achieve the transfer of pollen. The number of hives used is determined by the crop and the availability of wild pollinators. There has been some use of leaf-cutter and alkaline bees, but these bees are hard to maintain, have narrow environmental working windows, and are difficult to obtain. When discussing the transfer of pollen by insects, it is also important to consider any other crops in the immediate area that may compete for insect pollinators. This is an especially important consideration for seed crops that have flowers that are not particularly attractive to bees because of poor pollen or nectar availability, or possibly unpalatable nectar or some repellent quality of the plant.

In addition to considering how many pollinators are needed and what crops may be nearby to compete for pollinators, it is important to determine the distance necessary to isolate a seed crop from other seed crops of the same species but different cultivar. Isolation distances are particularly important to insect-andwind-pollinatedcrops. Usually isolation distances are much greater in insect- than wind-pollinated crops, and isolation distances increase between cultivars of the same species when they differ in shape, size, type, or color. In most of the major western vegetable seed production locations, seed companies have recognized the mutual benefit of isolation distances and have established isolation mapping systems. Using a county or local governing body, such as an irrigation district, seed companies have volunteered to pin down potential crop locations and also to abide by agreed-upon isolation distances. This mapping procedure is usually on a first-come first-served basis.

As with any step in the production of vegetable seed, "finishing-off" the crop is as important as any other step. Finishing-off refers to all the steps needed to bring the seed crop through maturity, to the determination of the time of seed harvest and the means by which seed harvest isaccomplished. Determination of harvest time and method is as varied as the crops. Many vegetable seed crops are mechanically windrowed and/or harvested, but some are hand-cut and windrowed or even handharvested. The environment plays a critical role at finishing-off. Unseasonable rains, early frosts, high winds, or high temperatures can doom a promising seed crop in a matter of hours. As mentioned earlier, one of the main reasons for the location of much of the seed production in the western United States is its favorable climate during seed harvest. Much of seed crop planning, site location, and planting time is concerned with the timing of harvest.

The effect of environment and cultural practices on seed quality has probably been recognized for as long as man has produced seed. University and public researchers have provided research and information on the effects of environment and cultural practices on seed quality, changing production practices and improving overall seed quality. Seed companiesadditionally have a long history of experimenting with new techniques for the production of vegetable seed. However, due to increased competition and concern over seed quality, some seed companies have hired seed scientists and/or put together research teams, which may include representatives from pathology, agronomy, plant breeding, entomology, and seed and plant physiology, to conduct specific research programs centered on seed production. The seed production researcher or team works closely with the production staff to conduct carefully controlled experiments dealing with changes in production and cultural practices for the improvement of seed yields and quality. This proprietary seed production research leads to improved production techniques, which may result ingreater seed yields and better quality, thus providing the company with an economic and quality edge over its competitorsand a higher-quality product for its customers. In-some areas this edge may be as or even more important than providing improved cultivars.

\section{Literature Cited}

Association of Official Seed Analysts. 1983. Seed vigor testing handbook. Assn. Offic. Seed Anal. Hndbk. 32. 